\title{
SEM/EDX Analysis of Fine Particulate Matter from the Exhaust Emission of Motorized Pedicabs (Kuligligs)
}

\author{
Maria Cecilia D. Galvez, Heidie C. Jayo, and Edgar A. Vallar \\ (Physics Department, De La Salle University, 2401 Taft Avenue, Malate, Manila, Philippines 1004)
}

\begin{abstract}
Fine particulate matter coming from the vehicular exhaust emission of motorized pedicabs (kuligligs) in Manila were characterized for its elemental composition using a scanning electron microscope (SEM) equipped with energy dispersive x-ray analysis (EDX). A personal cascade impactor, placed at the tailpipe of the "kuligligs", was used to collect the fine particulate matter coming from its exhaust emission. EDX analysis revealed that the particles coming from the emission of these "kuligligs" have complex compositions, which includes several elements like $\mathrm{Na}, \mathrm{Mg}, \mathrm{Si}, \mathrm{P}, \mathrm{S}, \mathrm{Cl}, \mathrm{K}, \mathrm{Ca}, \mathrm{Sc}, \mathrm{Ti}, \mathrm{V}, \mathrm{Cr}, \mathrm{Mn}, \mathrm{Fe}, \mathrm{Co}, \mathrm{Ni}, \mathrm{Cu}$, $\mathrm{Zn}, \mathrm{Br}, \mathrm{Sr}, \mathrm{Cd}, \mathrm{Sn}, \mathrm{Sb}, \mathrm{Ba}, \mathrm{Hg}$, and $\mathrm{Pb}$.
\end{abstract}

Keywords - boat engine, elemental analysis, fine particulate matter, "kuliglig", SEM/EDX

\section{INTRODUCTION}

In recent years, the investigation of fine particulate matter (PM) with size smaller than $2.5 \mu \mathrm{m}$ has received great attention because of its effect on human health. It is sometimes called respirable particles because it penetrates deep into the lungs [1]. In the Philippines, vehicular emission is the major source of air pollution. Shown in Fig. 1, motorized pedicabs, or popularly known as "kuliglig", has become a popular mode transportation for short distances in the busy roads of Manila. "Kuligligs" are ordinary pedicabs improvised with engines commonly used in motorized farm carts also called "kuliglig". The shape of this farm cart looks like an insect called cricket, which is "kuliglig" in Filipino term. Some say it is also called "kuliglig" because of the noise that it makes. The "kuliglig" engine was originally intended for the use of a banca (fishing boat) that's why it can also be called a "tricyboat" because it looks like a tricycle using a boat engine [2]. In the 1970's, farmers attached wooden carts with makeshift seats on the engine so that it could transport people and agricultural supplies in farms. Some of the engines used by these "kuligligs" were second-hand. It is considered as a "nonroad" engine. A "nonroad" engine covers a diverse collection of engines, equipment, and vehicles which can also be referred to as "off-road" or "off-highway". The nonroad category also includes outdoor power equipment, recreational vehicles, farm and construction equipment, boats, and locomotives [3]. Nonroad sources also emit other pollutants commonly referred to as air toxics, which include carcinogens, mutagens, and reproductive toxins [3]. A "kuliglig" uses a two-stroke engine which generally utilizes a fuel and oil mixture to produce power while lubricating the engine. In a two-stroke engine, as much as $30 \%$ of the intake charge passes through the engine unburned and is exhaust to the atmosphere. Thereby producing high emissions of particulate matter, hydrocarbons ( $\mathrm{HC})$, and carbon monoxide compared to a four-stroke engine [4].

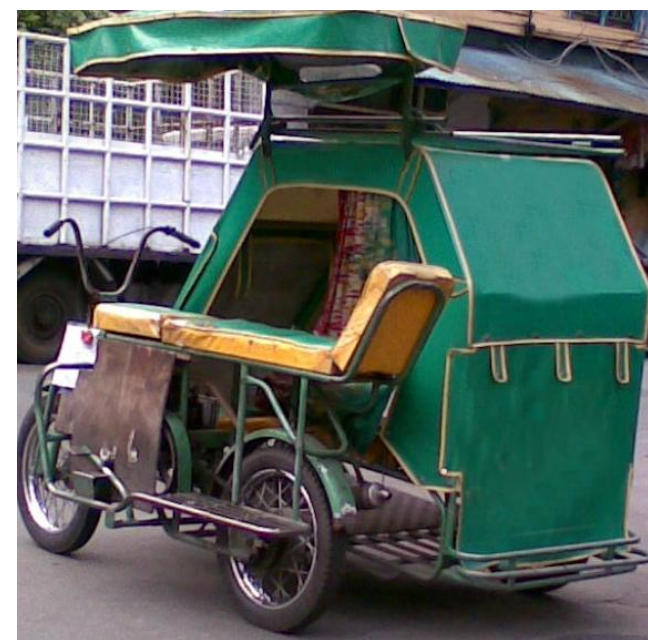

Figure 1. (a) The motorized pedicabs or "kuliglig". of Manila.

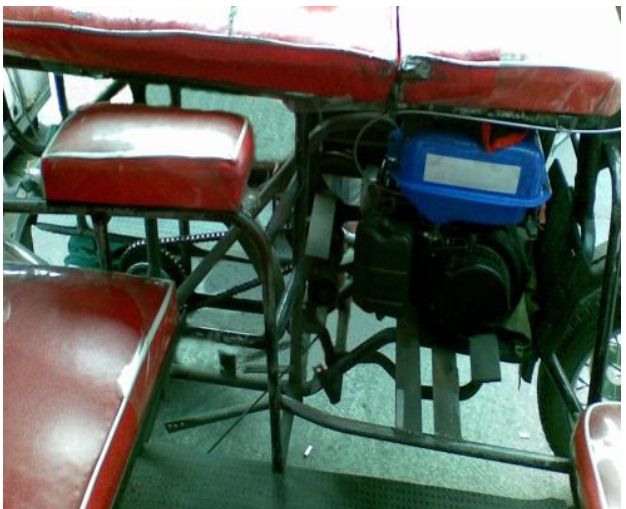

(b) The engine of a "kuliglig" plying the major roads 
Further, the misuse of lubricants can affect the level of hydrocarbon and particulate matter emission of a twostroke engine. However, most drivers add more lubricants because of the lack of knowledge of the correct amount to be used and they think that it will increase fuel economy [5]. In the last quarter of the year 2010, Executive Orders Nos. 16 and 17 were issued by the Manila City Government prohibiting "kuligligs" to ply the Ermita-Malate area, the stretch of Taft Avenue from Lawton to Vito Cruz, Roxas Boulevard and all major roads in Manila. This was because of "mounting complaints against their continued operation that allegedly causes pollution and contributes to the worsening traffic situation". Unfortunately, the said impact of "kuligligs" to traffic and pollution was, however, not significantly explained. They are considered as illegal vehicles because there is no government law that stipulates the authorization of such type of vehicle that uses a unique engine. Hence, they cannot be registered with the Land Transportation Office (LTO). Furthermore, the engine used in this kind of vehicle is not subject to any emission testing in the Philippines. In this paper we aim to provide the elemental composition of fine particulate matter coming from the exhaust emission of this new type of vehicle plying the roads of Manila using a scanning electron microscope equipped with energy dispersive X-ray analysis (SEM/EDX). Air sampling of the exhaust emission of "kuliglig" was done using a personal cascade impactor.

\section{METHODOLOGY}

Fine particulate matter coming from the exhaust tailpipe of the "kuliglig" was collected using a personal 2-stage low-volume cascade impactor which is shown in Fig. 2. The impactor was made from aluminum and had a nozzle diameter of $0.4 \mathrm{~mm}$. A more detailed description of the personal 2-stage lowvolume cascade impactor is given in [6]. Particles were impacted on an 8-mm diameter aluminum foil which was prepared using a thoroughly cleaned and sonicated $8-\mathrm{mm}$ hole puncher. A small amount of ethanol was applied to the aluminum foil after it was cut to a diameter of $8 \mathrm{~mm}$ to remove impurities. For the elemental composition and morphological features of the fine particulate matter collected, a scanning electron microscope equipped with energy dispersive X-ray analysis (SEM/EDX) was used. The SEM used was JSM 5310 JEOL Scanning Electron Microscope that was operated at acceleration voltages of $15 \mathrm{kV}$. The microscope is equipped with an Oxford energy dispersive X-ray analyzer where the elemental composition of the particulate matter was obtained. The SEM images and analytical data of trace elements concentration were recorded using a Link Isis 3.0 software system with a SemAfore 5.0 SA20 Scan Digitizer for digital imaging. Particle size was estimated from the direct appearance of individual particles in the scanning electron micrograph. SEM/EDX was done according to the standard operating procedure for sample preparation and analysis of particulate matter samples by scanning electron microscopy. The instrument acquires either single spot spectrum or area spectrum, in this way it is possible to identify a single particle analysis and the mean values of the constituents from a group of particles.

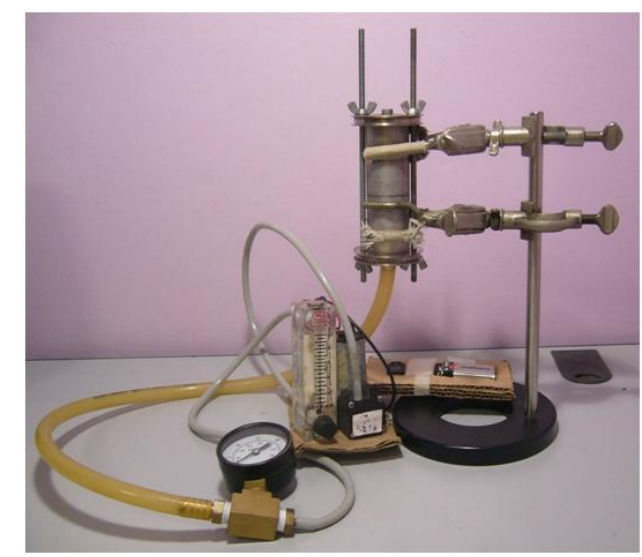

Figure 2. The two-stage personal cascade impactor. 


\section{RESULTS AND DISCUSSION}
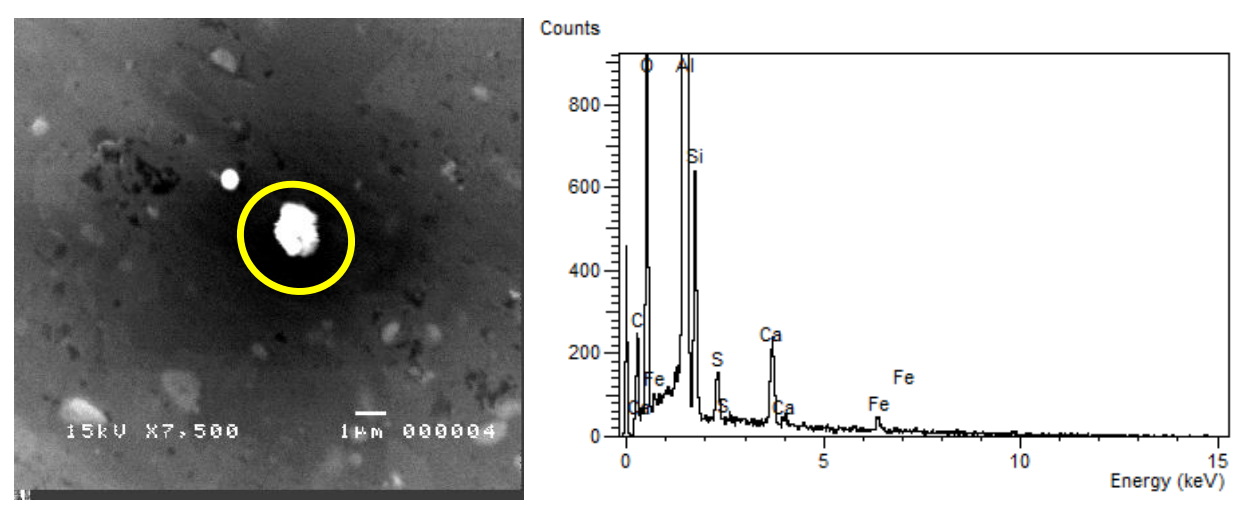

Figure 3. SEM image of a PM2.5 sample at a magnification of 7500x and the corresponding EDS spectrum. The particle encircled has a diameter of $1.93 \mu \mathrm{m}$ and is composed of mostly Carbon (18\%), Oxygen (44\%), Silicon (15\%), Sulfur (0.99\%), Calcium $(2.46 \%)$, and Iron (1\%).

The three "kuligligs" used in this study differed in manufacturing year (2006, 2008, and 2010) and will be referred to as K1, K2, and K3, respectively. The "kuligligs" sampled used unleaded gasoline with unknown specifications of boat engines. Among the three, K3 used a new boat engine while the other two used secondhand boat engines. Twenty (20) particles with a diameter not greater than $2.5 \mu \mathrm{m}$ were selected for each "kuliglig" for analysis and detection of elemental composition and concentration (in wt \%). Figure 3 shows an example of an SEM image of one of the fine particulate matter analyzed and the corresponding EDS spectrum. Aluminum foil was used as the impaction substrate for this type of vehicle. Aside from Carbon (C) and Oxygen (O), Sodium (Na), Magnesium (Mg), Silicon (Si), Sulfur (S), Phosphorous (P), Chlorine (Cl), Potassium (K), Calcium (Ca), Scandium (Sc), Titanium (Ti), Vanadium (V), Chromium (Cr), Manganese (Mn), Iron (Fe), Cobalt (Co), Nickel (Ni), Copper (Cu), Zinc ( $\mathrm{Zn})$, Bromine (Br), Strontium (Sr), Cadmium (Cd), Tin (Sn), Antimony $(\mathrm{Sb})$, Barium $(\mathrm{Ba})$, Mercury $(\mathrm{Hg})$ and Lead $(\mathrm{Pb})$ were among the elements found in some of the particles analyzed. Figure 4 shows the frequency of occurrence of these elements on the fine particulate matter analyzed for each "kuliglig". The hazardous element Selenium (Se) was detected only on all the fine particulate matter analyzed on K1 and was not detected at all in any of the fine particulate matter analyzed on K2 and K3. Figure 5 shows a box plot of the concentration (in wt \%) of the elements detected on the PM collected from the exhaust emissions of (a) "kuliglig" 1, (b) "kuliglig" 2, and (c) "kuliglig" 3. Metals like Fe, $\mathrm{Cu}$, and Zn have a high frequency of occurrence for the three "kuligligs". Cu particles from the engine are either present as metal wear or as a chemical compound dispersed into the oil and as a possible gasoline engine oil additive [6]. Fe may have come from the cylinders, rotating shafts, the valve train, and any steel part sharing the oil while $\mathrm{Zn}$ is included in engine oil as an anti-wear additive [7]. Among the three "kuligligs", K2 had the most number of major and minor elements, as seen from Fig. 5. Elements like $\mathrm{Sr}, \mathrm{Hg}$, and $\mathrm{Pb}$ were major elements (found in more than $50 \%$ of the particles analyzed) for K2 while they are only minor elements for K1 and K3. Sr, Ba and Co, were also detected in some of the particles analyzed for all the three "kuligligs" and are inorganic exhaust

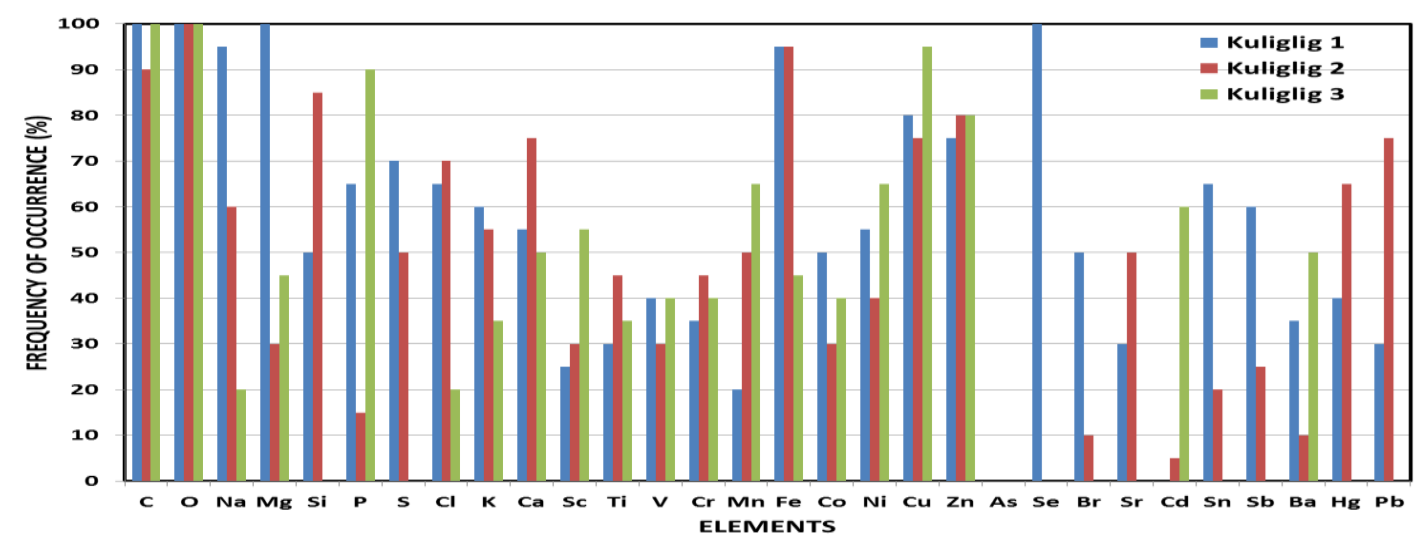

Figure 4. Frequency of occurrence of the elements detected on the fine particulate matter analyzed for each "kuliglig". 

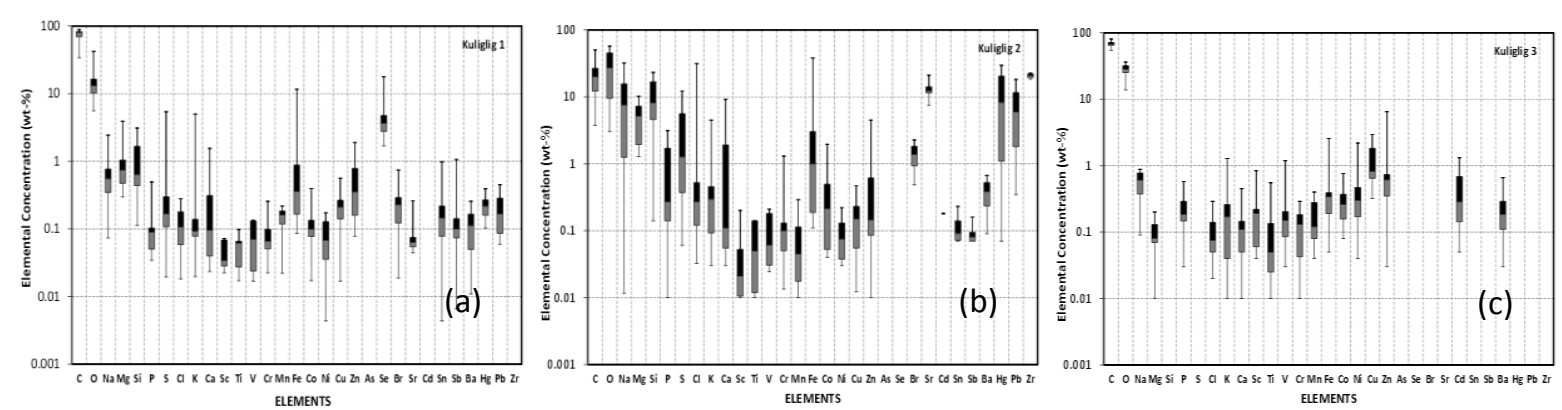

Figure 5. Concentration (in wt \%) of elements found in the fine particulate matter collected from the exhaust emissions of (a) "kuliglig" 1; (b) "kuliglig" 2; (c) "kuliglig" 3.

components produced from engine and component wear, or are trace contaminants of the fuel and/or lubricant oil which usually vaporize in the combustion chamber and then "plate" themselves to particles in the exhaust stream [8]. Although unleaded gasoline was used, $\mathrm{Pb}$ may still occur in the exhaust gas coming from the fuel and from the worn metal alloys in the engine [9]. Gasoline, diesel, and LPG contain certain amount of Hg and, in a study made by Won et. al., they found out that vehicles, whether in idling or driving mode, emit $\mathrm{Hg}$ in its elemental form [10]. Other elements detected like $\mathrm{Ba}, \mathrm{K}, \mathrm{P}, \mathrm{Zn}, \mathrm{Mg}, \mathrm{Mn}$, and $\mathrm{Co}$ are fuel additives. $\mathrm{Cr}$ is a trace element in steel and may come from wear of engine components [11]. $\mathrm{V}$ is also present in petroleum products. Ni is present in fuel and as a trace element in steel whereas $\mathrm{Ti}$ is a trace element in gasoline.

\section{CONCLUSION}

This is the first study, using the SEM/EDX technique, to determine the elemental composition of fine particulate matter from the exhaust emission of three "kuligligs" which use boat engines. The study revealed that the fine particulate matter coming from the exhaust emission of the three "kuligligs" have complex compositions that include several hazardous elements in minor or trace amounts. The composition includes $\mathrm{Na}$, $\mathrm{Mg}$, Si, P, S, Cl, K, Ca, Sc, Ti, V, Cr, Mn, Fe, Co, Ni, Cu, Zn, Br, Sr, Cd, Sn, Sb, Ba, Hg and Pb. Hazardous element Se was detected only on K1. However, it was present on all the fine particulate matter analyzed for K1. "Kuliglig" K2 was found to emit fine particulate matter that have major concentration (in wt\%) of hazardous elements like $\mathrm{Hg}$ and $\mathrm{Pb}$. The study is very important since this kind of vehicle still continue to ply the major roads of Manila and also the side streets, although they were prohibited in 2010 from doing so via a Manila City government ordinance. Furthermore, the engines they are using are not among engines being regulated, at least for emission testing, by the concerned government agency. This study is very useful so that we can have some information on the composition of the fine particulate matter that this vehicle emits and this is very important because of the effect that fine particulate matter has on the people's health.

\section{REFERENCES}

[1] M. C. D. Galvez, H. C. Jayo, V. R. Morris, and E. A. Vallar, Elemental Composition of Fine Particulate Matters from the Exhaust Emission of Jeepneys Plying the Route of Taft Avenue, Manila, Philippines, International Journal of Modern Engineering Research, 3 (1), Jan.-Feb. 2013, 406-410.

[2] CAI-Asia, Cost-benefit Analysis of Technology and Replacement Options for 2-stroke Three Wheelers in the Philippines July 2011, Pasig City, Philippines, 2011.

[3] US-EPA, Nonroad Engine and Vehicle Emission Study-Report, Washington, DC, U.S.A, 1991.

[4] US-EPA, Control of Emissions From Nonroad Large Spark Ignition Engines, Recreational Engines (Marine and Land-Based), and Highway Motorcycles, Federal Register Proposed Rules, 65(236), December 7, 2000, 76797-76829.

[5] M. Kojima, C. Brandon, and J. Shah, Improving Urban Air Quality in South Asia by Reducing Emissions from Two-Stroke Engine Vehicle, The International Bank for Reconstruction and Development, The World Bank, Washington, D.C., U.S.A., December 2000.

[6] H.C. Jayo, Elemental Composition of Fine Particulate Matter from Vehicle Exhaust Emissions Analyzed Using Scanning Electron Microscopy with Energy Dispersive X-Ray Analysis, bachelor theses, De La Salle University, Manila, Philippines, 2011.

[7] Blackstone laboratories, 2006. Available at: http://www.blackstone-labs.com/gasoline_diesel_report_expl.html.

[8] R. K. Krieger, J. M. Brooks, G. A. Shiroma, D. J. Ames, and P. D. Venturini, Part A. Public Exposure To, Sources and Emissions of Diesel Exhaust in California, Report to the Air Resources Board on the Proposed Identification of Diesel Exhaust as a Toxic Air Contaminant, 1998.

[9] M. Winther and E. Slentø, Heavy Metal Emissions for Danish Road Transport, National Environmental Research Institute, Aarhus University, Denmark. 99 pp. - NERI Technical Report no. 780. Available online: http://www.dmu.dk/Pub/FR780.pdf.

[10] J. H. Won, J. Y. Park, and T. G. Lee, Mercury emissions from automobiles using gasoline, diesel, and LPG, Atmospheric Environment, 4, 2007, 7547-7552.

[11] D. G. Sharheen, Contributions of urban roadway usage to water pollution, EPA-600/2-75-004, 1975. 